OPEN ACCESS

Edited by: Giovanna Suzzi,

University of Teramo, Italy

Reviewed by:

Natasa Golic,

Institute of Molecular Genetics and Genetic Engineering, Serbia

Giorgia Perpetuini,

University of Teramo, Italy

${ }^{*}$ Correspondence:

Yunhe Xu

sn_97@126.com

Specialty section:

This article was submitted to

Food Microbiology,

a section of the journal

Frontiers in Microbiology

Received: 01 April 2017

Accepted: 11 July 2017

Published: 25 July 2017

Citation:

Zhang L, YU Y, Li X, Li X, Zhang H, Zhang $Z$ and $X u Y(2017)$ Starch Flocculation by the Sweet Potato

Sour Liquid Is Mediated by the Adhesion of Lactic Acid Bacteria to Starch. Front. Microbiol. 8:1412. doi: 10.3389/fmicb.2017.01412

\section{Starch Flocculation by the Sweet Potato Sour Liquid Is Mediated by the Adhesion of Lactic Acid Bacteria to Starch}

\author{
Lili Zhang ${ }^{1,2}$, Yang Y $u^{1}$, Xinhua $L^{3}$, Xiaona Li $^{3}$, Huajiang Zhang ${ }^{4}$, Zhen Zhang ${ }^{1}$ and \\ Yunhe $X u^{1 *}$
}

1 Department of Food Science and Engineering, Jinzhou Medical University, Jinzhou, China, ${ }^{2}$ Liaoning Provincial Research Center of Meat Processing and Quality Control, Jinzhou, China, ${ }^{3}$ Department of Food Science, Shenyang Agricultural University, Shenyang, China, ${ }^{4}$ Department of Food Science, Northeast Agricultural University, Harbin, China

In the current study, we focused on the mechanism underlying starch flocculation by the sweet potato sour liquid. The traditional microbial techniques and 16S rDNA sequencing revealed that Lactobacillus was dominant flocculating microorganism in sour liquid. In total, 86 bacteria, 20 yeasts, and 10 molds were isolated from the sour liquid and only eight Lactobacillus species exhibited flocculating activity. Lactobacillus paracasei subsp. paracasei L1 strain with a high flocculating activity was isolated and identified, and the mechanism of starch flocculation was examined. L. paracasei subsp. paracasei L1 cells formed chain-like structures on starch granules. Consequently, these cells connected the starch granules to one another, leading to formation of large flocs. The results of various treatments of $L 1$ cells indicated that bacterial surface proteins play a role in flocculation and L1 cells adhered to the surface of starch granules via specific surface proteins. These surface starch-binding proteins were extracted using the guanidine hydrochloride method; 10 proteins were identified by mass spectrometry: three of these proteins were glycolytic enzymes; two were identified as the translation elongation factor Tu; one was a cell wall hydrolase; one was a surface antigen; one was lyzozyme M1; one was a glycoside hydrolase; and one was an uncharacterized proteins. This study will paves the way for future industrial application of the $L 1$ isolate in starch processing and food manufacturing.

Keywords: lactic acid bacteria, starch flocculation, starch-binding proteins, sweet potato sour liquid, natural fermentation

\section{INTRODUCTION}

The processing of starch flocculated with sour liquid has a 400-year history in China (Research Groups of Sour Liquid, 1974). Sour liquid is milky-white or yellowish-white, with a sour taste, and it is generated by natural fermentation. It is used as a flocculant, as it accelerates starch flocculation and shortens the settling time of starch (Research Groups of Sour Liquid, 1974; Wei and Qun, 2007). The technology of sour liquid-aided flocculation is mainly used for the processing of sweet potato starch or mung bean starch. 
It has been reported that microorganisms present in the sour liquid are responsible for the flocculation of starch. Streptococcus lactis from a mung bean sour liquid was isolated, and shown to bind to the starch granules, and promote the flocculation of starch (Xu and Liu, 1980). In addition, flocculation is affected by temperature, $\mathrm{pH}$, free ion concentration, and other factors (Research Groups of Sour Liquid, 1974). However, the mechanism by which $S$. lactis flocculates starch is still unclear. This restricts the application of the sour liquid technology in the processing of other plant starches or in large-scale industrialization.

Although the mechanism by which lactic acid bacteria bind to and flocculate starch remains unclear, the starch-binding activity of bacteria has been investigated in Bifidobacterium, Bacteroides thetaiotaomicron, Lactobacillus amylovorus, and Vibrio cholerae cells (Reeves et al., 1996, 1997; Crittenden et al., 2001; Rodriguez-Sanoja et al., 2005; Ryan et al., 2006; Niderman-Meyer et al., 2010). Researchers found that bacteria from the Bifidobacterium genus possess a strong starch-binding ability, and are absorbed and embedded in resistant starch granules (Crittenden et al., 2001). These characteristics have been exploited during preparation of probiotic microcapsules, markedly decreasing the difficulties associated with the production of these microcapsules (Crittenden et al., 2001). The starch-binding activity of $B$. thetaiotaomicron plays an important role in starch metabolism in the mammalian gut (Shipman et al., 2000; Crittenden et al., 2001). Drugs with resistant starch as an adjuvant are characterized by a relatively good efficacy in treating acute gastroenteritis caused by $V$. cholerae; this species can specifically bind to the surface of resistant starch granules, thus accelerating the discharge of $V$. cholerae from the body (Niderman-Meyer et al., 2010). The starch-binding activity of B. thetaiotaomicron, a Gramnegative bacterial species, is mediated by the outer membrane proteins SusC, SusD, SusE, and SusF (Donaldson et al., 2016; O'Toole, 2016). Similarly, starch binding by Bifidobacterium involves specific cell surface proteins rather than non-specific hydrophobic and electrostatic interactions; however, the property of proteins that participate in the adhesion of Bifidobacterium to starch remains unclear (Crittenden et al., 2001). Starchbinding activities of these bacteria are closely associated with their cell wall proteins (Shipman et al., 2000; Crittenden et al., 2001).

In the current study, we focused on the naturally fermented sour liquid of the sweet potato. The V4 regions of $16 \mathrm{~S}$ rRNA genes of bacteria present in that liquid were analyzed by high-throughput sequencing, in conjunction with traditional microbial isolation and culture techniques, to determine the dominant microorganisms with starchbinding and flocculating activities. The mechanism of starch flocculation was then elucidated at a cellular level. Proteins that mediated the lactic acid bacteria binding to starch were identified by mass spectrometry. The results will provide theoretical basis for enhanced sour liquid application in the processing of starch for bean vermicelli production, and for the use of starch-binding lactic acid bacteria in food manufacturing.

\section{MATERIALS AND METHODS}

\section{Materials}

The sweet potato sour liquid was obtained from Yingnahe Starchworks (Dalian City, Liaoning Province, China). The sour liquid ( $1 \mathrm{~L}$ ) was collected in a sterile culture flask and transferred to a laboratory at $4^{\circ} \mathrm{C}$. Microorganisms were plated for enumeration and isolation on the same day. Sweet potato starch was purchased from Shandong Bio Sunkeen, Co., Ltd. (Jining City, China). Phosphate-buffered saline (PBS, pH 7.2) was purchased from Sigma Chemical, Co. (St. Louis, MO, United States). All other chemical reagents were of analytical grade.

The sweet potato juice medium was prepared as follows. Sweet potato infusion was prepared by boiling $200 \mathrm{~g}$ of sliced (washed but unpeeled) sweet potatoes in $1 \mathrm{~L}$ of distilled water for $30 \mathrm{~min}$, and decanting or straining the broth through cheesecloth. Distilled water was added such that the total volume of the suspension was $1 \mathrm{~L} ; 20 \mathrm{~g}$ of glucose, $2 \mathrm{~g}$ of lactose, $5 \mathrm{~g}$ of yeast extract, and $5 \mathrm{~g}$ of sodium acetate was then added, and the medium was sterilized by autoclaving at $115^{\circ} \mathrm{C}$ for $15 \mathrm{~min}$.

\section{Microorganism Counts and Isolation}

Microorganisms were enumerated and isolated by serial dilution and plating. Bacterial counts and isolation were conducted on Tomato Juice Agar (TJA) media supplemented with cycloheximide $(50 \mu \mathrm{g} / \mathrm{mL}$ ) to inhibit fungal growth (Muyanja et al., 2003; Lin et al., 2006). The plates were incubated at $30^{\circ} \mathrm{C}$ for $24 \mathrm{~h}$. Yeasts and molds were inoculated on Rose Bengal agar plates and incubated at $30^{\circ} \mathrm{C}$ for 3-5 days (Coombs and Franco, 2003). To distinguish between the two, colonies that were smooth and wet were considered as yeasts; downy or furry colonies were considered to be molds. Bacterial colonies were counted using automatic colony counters (Interscience Scan 1200). Colonies with distinct morphological characteristics were selected and transferred onto sweet potato juice slant medium (vide infra), cultured at $30^{\circ} \mathrm{C}$ (bacteria for 1 day, yeasts for 3 days, and molds for 5 days), and were then stored at $-4^{\circ} \mathrm{C}$ to screen the strains with high flocculating activities (Anastasi et al., 2005).

\section{Screening Methods}

The selected strain slopes were inoculated into $5 \mathrm{~mL}$ of sweet potato juice medium and cultured at $30^{\circ} \mathrm{C}$. Bacteria and yeasts were cultured for 1 and 3 days, respectively. The molds were cultured with shaking at $160 \mathrm{rpm}$ for 5 days. Then, the flocculation rate of fermentation liquor was determined as the flowing methods. Using the flocculation rate of the cultures as an index, with the sweet potato juice medium as a control, the strains were screened for high flocculating starch activity.

\section{Flocculation Rate (FR) Measurements}

Distilled water $(100 \mathrm{~mL}), 0.5 \mathrm{~g}$ of sweet potato starch, and $5 \mathrm{~mL}$ of the liquor to be tested were placed in a $150-\mathrm{mL}$ beaker. The liquid was agitated for 3 min on a magnetic stirring apparatus, and then left to stand for $3 \mathrm{~min}$. As a control, sweet potato juice was used instead of the fermented liquor. The flocculation efficiency was expressed as FR, by measuring the decrease of turbidity of the 
upper phase (Lian et al., 2008; Beck et al., 2009; Bhattacharya et al., 2017). FR was calculated by the following equation:

$$
\mathrm{FR}(\%)=\frac{\mathrm{A}-\mathrm{B}}{\mathrm{A}} \times 100 \%
$$

Where A and B are optical densities of the control and sample, respectively, at $550 \mathrm{~nm}$.

\section{Bacterial Sampling for 165 rDNA Sequencing}

Microbial genomic DNA was extracted from $1 \mathrm{~mL}$ of the sour liquid by using the TIANGEN DNA stool mini kit (TIANGEN, cat\#DP328) according to the manufacturer's instructions. The V4 variable region of $16 \mathrm{~S}$ rDNA was amplified using the universal primers 520F (5'-AYTGGGYDTAAAGNG-3') and 802R ( $5^{\prime}$-TACNVGGGTATCTAATCC-3') (Blanton et al., 2016). The PCR amplification and the construction of a sequencing library were performed, as described previously (Xu et al., 2016). For each sample, barcoded V4 PCR amplicons were sequenced using the Illumina MiSeq platform (Dong et al., 2015; Donaldson et al., 2016). Amplification and sequencing of the V4 variable region of $16 \mathrm{~S}$ rDNA was completed by Personal Biotechnology, Co., Ltd. (Shanghai, China).

Sequence reads were excluded from analysis if their length was less than $150 \mathrm{bp}$, the average Phred score was lower than 20, contained ambiguous bases, a homopolymer run exceeding six bases, or when mismatches in primers were detected. Sequences that passed quality filtering were then assembled by Flash ${ }^{1}$, which required that the overlap of reads 1 and 2 was $\geq 10 \mathrm{bp}$, without any mismatches. The reads that could not be assembled were discarded. Chimera sequences were removed using UCHIME in mothur (version $1.31 .2^{2}$ ).

\section{Operational Taxonomic Unit (OTU) Clustering}

Sequence clustering was performed using UCLUST algorithm in $\mathrm{QIIME}^{3}$; the sequences were clustered into operational taxonomic units (OTUs). The longest sequence in each cluster was selected as the representative. The taxonomy of each OTU was assigned by BLAST-searching the representative sequence against Greengenes reference database (Release $13.8^{4}$ ) (Xu et al., 2016).

\section{Strain Identification by 16 S rDNA Sequencing}

Pure isolates were grown to a late stationary phase in $5 \mathrm{~mL}$ of media. The cultures were centrifuged for $10 \mathrm{~min}$ at $4,000 \times g$. Each cell pellet was resuspended in $0.5 \mathrm{~mL}$ of $\mathrm{dH}_{2} \mathrm{O}$, and DNA was extracted using the TIANGEN DNA stool mini kit (TIANGEN, cat\#DP328) according to the producer's instructions.

\footnotetext{
${ }^{1}$ http://ccb.jhu.edu/software/FLASH/

${ }^{2}$ http://www.mothur.org/

${ }^{3}$ http://qiime.org/scripts/pick_otus.html

${ }^{4} \mathrm{http} / /$ greengenes.secondgenome.com/
}

Full-length $16 \mathrm{~S}$ rDNA amplicons were generated with bacterial primers 27F (5'-AGAGTTTGATCCTGGCTCAG-3') and 1492R ( $5^{\prime}$-CTACGGCTACCTTGTTACGA-3'). The PCR amplification and sequencing were performed, as described previously (Piotrowska et al., 2016).

To identify $16 \mathrm{~S}$ rDNA sequences most similar to the obtained sequences, all sequences were matched against nucleotide sequences deposited in GenBank using the BLASTn program ${ }^{5}$.

Finally, strain identification based on its colony character, morphological, and physiological characteristics, as well as $16 S$ rDNA sequence homology referencing Bergey's Manual of Systematic Bacteriology.

\section{Preparation of the L. paracasei subsp. paracasei L1 Fermentation Liquor}

Lactobacillus paracasei subsp. paracasei L1 slope were inoculated into a tube of fermented sweet potato juice $(5 \mathrm{~mL})$ and were cultured for $24 \mathrm{~h}$ at $30^{\circ} \mathrm{C}$. Then, the inoculum was inoculated into the sweet potato juice medium (5\%,v/v) and cultured for $24 \mathrm{~h}$ at $30^{\circ} \mathrm{C}$.

Flocculation activity of $\mathrm{L} 1$ in fermentation liquor was as follows. Five milliliter of the fermented liquor were centrifuged at $4,000 \times g$ for $10 \mathrm{~min}$. The cell pellet was washed twice with distilled water; $5 \mathrm{~mL}$ of distilled water was added to obtain a bacterial suspension. Distilled water $(100 \mathrm{~mL}), 0.5 \mathrm{~g}$ of sweet potato starch, and $5 \mathrm{~mL}$ of the bacterial suspension were placed in a $150-\mathrm{mL}$ beaker to test the flocculation activity.

\section{Flocculating Activity of Lactobacillus paracasei subsp. paracasei L1 in Fermentation Liquor}

Lactobacillus paracasei subsp. paracasei L1 culture $(10 \mathrm{~mL})$ was centrifuged at $4,000 \times g$ for $10 \mathrm{~min}$. The cell pellet was washed twice with $\mathrm{dH}_{2} \mathrm{O}$, and $10 \mathrm{~mL}$ of distilled water was added to obtain a bacterial suspension. Flocculating activities of culture broth, cell-free supernatant and cell pellet were tested (Lian et al., 2008).

\section{Determination of the Particle Size of Starch Granules before and after Flocculation}

Lactobacillus paracasei subsp. paracasei L1 cultures $(10 \mathrm{~mL})$ were centrifuged at $4,000 \times g$ for $10 \mathrm{~min}$. The cell pellet was washed twice with distilled water; $10 \mathrm{~mL}$ of distilled water was added to obtain a bacterial suspension. Distilled water $(100 \mathrm{~mL}), 0.5 \mathrm{~g}$ of sweet potato starch, and $5 \mathrm{~mL}$ of the bacterial suspension were placed in a $150-\mathrm{mL}$ beaker. Microtrac laser particle size analyzer (S3500, American Microtrac Company) and laser diffraction particle size distribution meter were used to determine the particle size distribution of sweet potato starch before flocculation. Thereafter, the liquid was agitated for $3 \mathrm{~min}$ on a magnetic stirring apparatus, and then left to stand for $3 \mathrm{~min}$. Microtrac S3500 was next used to determine the particle size

${ }^{5}$ www.ncbi.nlm.nih.gov/blast 
distribution of starch and in the supernatant after flocculation (Biggs et al., 2000; Hjorth and Jørgensen, 2012).

\section{Microscopic Observation of Starch Granules with Adhered Bacteria}

Sweet potato starch granules were observed by optical microscopy before and after the addition of $L$. paracasei subsp. paracasei L1 fermentation liquor. Samples of starch granules with adhered bacteria were fixed with a glutaraldehyde solution [3\% $(\mathrm{v} / \mathrm{v})$ in $0.01 \mathrm{M}$ phosphate buffer, $\mathrm{pH}$ 7.2] on brass stubs and chromium-coated by Xenosput 2000 chromium coater with the deposition parameters of 0.06 sputter Amps for 40 s. Coated preparations were visualized with Hitachi S4800 scanning electron microscope (SEM; Japanese Hitachi Ltd) at the accelerating voltage of $2 \mathrm{kV}$ (O'Riordan et al., 2001).

\section{Determination of Zeta ( $\zeta$ ) Potential during the Flocculation Process}

Sweet potato starch milk $(100 \mathrm{~mL})$ was weighed and tested by zeta potentiometer (nano-ZS, British Malvern). The values of $\zeta$ potential of sweet potato starch milk, L. paracasei subsp. paracasei L1 suspension, and sweet potato starch milk supplemented with $10 \%$ of $L$. paracasei subsp. paracasei L1 cells were determined (Hjorth and Jørgensen, 2012).

\section{Determining the Effect of Physical, Chemical, and Enzymatic Treatments on the Flocculating Activity of $L$. paracasei subsp. paracasei L1 Cells}

Lactobacillus paracasei subsp. paracasei L1 cells were cultured for $24 \mathrm{~h}$ in the sweet potato juice medium, washed twice with PBS, and collected by centrifugation. The specific experiments were performed as follows: cells were resuspended in PBS to 8 $\log \mathrm{CFU} / \mathrm{mL}$ and then heat-treated in a water bath at 30,40 , 50 , and $60^{\circ} \mathrm{C}$ for $30 \mathrm{~min}$. Next, cells were resuspended in PBS to $8 \log \mathrm{CFU} / \mathrm{mL}$ and then irradiated using an ultraviolet lamp $(18 \mathrm{~W}, 15 \mathrm{~cm}, 3 \mathrm{~h})$. Cells were resuspended in PBS to $8 \mathrm{log}$ $\mathrm{CFU} / \mathrm{mL}$ and then placed in an ice-water bath and sonicated for 5 min (CFS-25A-ultrasonic generator 8.6 kc, $250 \mathrm{~W}$ ). Processing was stopped when the temperature reached values $\geq 15^{\circ} \mathrm{C}$. When cells cooled to below $10^{\circ} \mathrm{C}$, they were again treated for $5 \mathrm{~min}$. When cells subsequently reached a temperature of $10^{\circ} \mathrm{C}$, treatment was repeated for $5 \mathrm{~min}$. Cells were pretreated with $3 \%$ trichloroacetic acid or $10^{-4} \mathrm{~mol} / \mathrm{L}$ lithium chloride at $28^{\circ} \mathrm{C}$ for $30 \mathrm{~min}$. Cells were resuspended in PBS to $8 \log \mathrm{CFU} / \mathrm{mL}$ and then separately pretreated with the following enzymes: trypsin (from bovine pancreas, Sigma; $3 \mathrm{mg}$ ) ml $\mathrm{m}^{-1}$, at $\mathrm{pH} 7.5$ for $6 \mathrm{~h}$ at $37^{\circ} \mathrm{C} ; \alpha$-amylase (from Bacillus licheniformis; $2 \mathrm{mg}$ ) $\mathrm{ml}^{-1}$ at $\mathrm{pH}$ 7.0 for $4 \mathrm{~h}$ at $40^{\circ} \mathrm{C}$; lysozyme (from egg white; $1 \mathrm{mg}$ ) ml ${ }^{-1}$ at $\mathrm{pH}$ 6.0 for $1 \mathrm{~h}$ at $37^{\circ} \mathrm{C}$. The flocculating experiment was performed using $3 \mathrm{~g}$ of Tween $80 \mathrm{~L}^{-1}$. Then, the flocculating experiment was performed using $5 \mathrm{~g} / \mathrm{L}$ of glucose or maltose (O'Riordan et al., 2001; Wei and Qun, 2007).

\section{Isolation of Starch-Binding Proteins}

Lactobacillus paracasei subsp. paracasei L1 was grown overnight in sweet potato juice medium, centrifuged $(10,000 \times g, 15 \mathrm{~min}$, $\left.4^{\circ} \mathrm{C}\right)$, and washed three times with PBS. The cells $(1 \mathrm{~g})$ were incubated in $20 \mathrm{~mL}$ of $4 \mathrm{M}$ guanidine hydrochloride with shaking (at $200 \mathrm{rpm}$ ) for $60 \mathrm{~min}$ at $37^{\circ} \mathrm{C}$. The supernatant was collected after centrifugation at $12,000 \times g$ and $4^{\circ} \mathrm{C}$ for $10 \mathrm{~min}$; it was dialyzed overnight in a dialysis bag, with PBS as the dialysis solution. PBS was replaced 5-6 times. Sweet potato starch $(0.5 \mathrm{~g})$ were added to $10-\mathrm{mL}$ samples of the supernatant, shaken for $30 \mathrm{~min}$ to ensure full exposure of granule surface to the supernatant, and then washed with PBS and centrifuged $\left(10,000 \times g, 5 \mathrm{~min}, 4^{\circ} \mathrm{C}\right)$, three times, to remove unbound proteins. To extract starch-bound proteins, each starch pellet was resuspended and incubated for $5 \mathrm{~min}$ in PBS (control) and PBS containing $100 \mathrm{mM}$ maltose. The starch was removed by centrifugation and the supernatant from each tube was separated and purified by sodium dodecyl sulfate polyacrylamide gel electrophoresis. The purified samples were digested with trypsin, analyzed by high performance liquid chromatography-electrospray ionization tandem mass spectrometry (LC-ESI-MS/MS) using Q Exactive (Thermo Scientific), and identified by Mascot 2.3.0 using the Uniprot Lactobacillus database $^{6}$ (Niderman-Meyer et al., 2010; Deng et al., 2013). The identification of starch-binding proteins by LC-ESIMS/MS was completed at Beijing Protein Innovation, Co., Ltd (Beijing, China).

\section{Statistical Analysis}

Data were obtained in triplicate and are reported as averages; Statistical analyses were performed to determine significant differences $(p<0.05)$ among obtained results using the Student's $t$-test or ANOVA followed by Duncan's multiple range test. All data were analyzed using the SPSS 16 software (SPSS, Chicago, IL, United States).

\section{RESULTS}

\section{Microbial Counts in the Sweet Potato Sour Liquid}

The counts of bacteria was the highest $(8.96 \pm 0.01 \log$ CFU $\mathrm{mL}^{-1}$ ). Yeasts were $5.04 \pm 0.04 \log \mathrm{CFU} \mathrm{mL} \mathrm{m}^{-1}$. Furthermore, molds were $2.71 \pm 0.02 \log \mathrm{CFU} \mathrm{mL} \mathrm{m}^{-1}$ and the lowest number in sour liquid. Bacteria, therefore, were dominant in the sour liquid.

\section{Bacterial Composition in the Sour Liquid Determined by 16S rDNA Sequencing}

To investigate the dominant bacteria in sour liquid, bacterial composition in the sour liquid was evaluated using highthroughput sequencing of the V4 regions of 16S rRNA genes. The bacterial community was analyzed at the genus level by comparing with Greengenes reference database. Acetobacter species were dominant in the liquid, accounting for $69.27 \%$

\footnotetext{
${ }^{6}$ http://www.uniprot.org/taxonomy/1578
} 


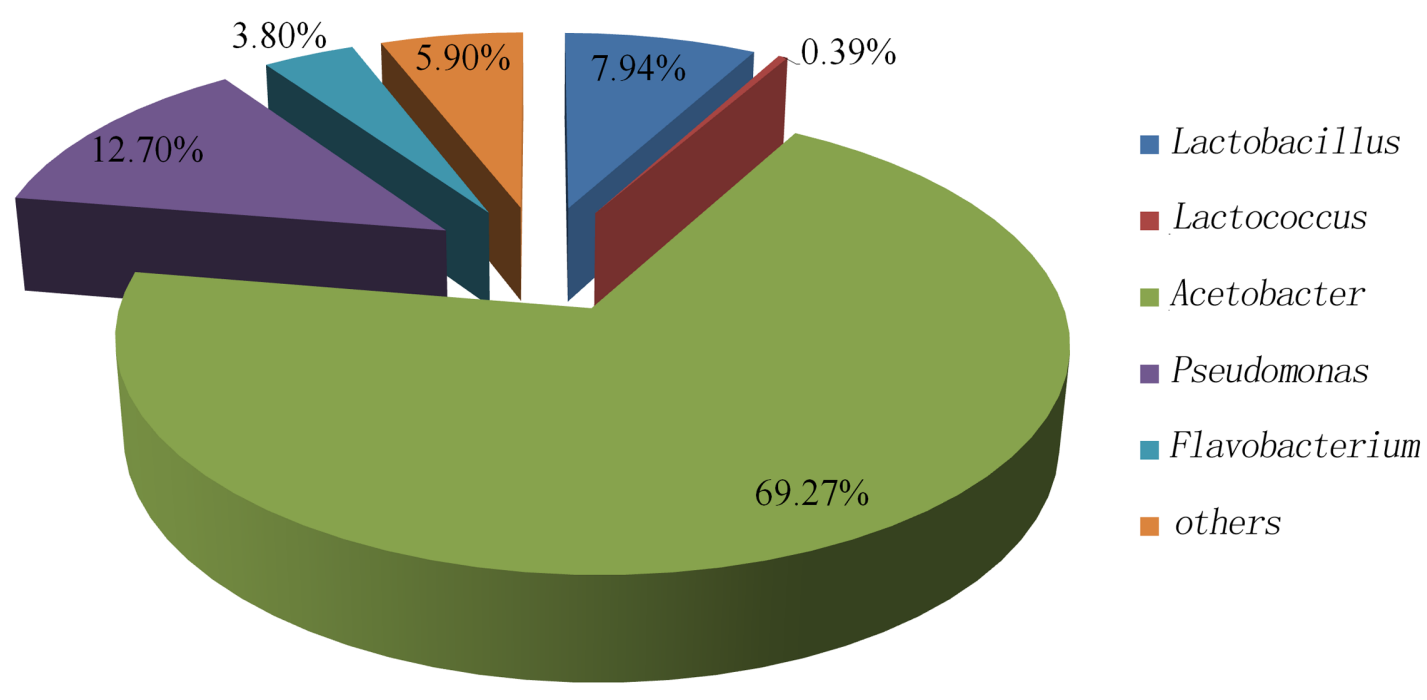

FIGURE 1 | The sour liquid bacterial community at genus level.

of bacteria in sour liquid; Pseudomonas species accounted for $12.70 \%$ of bacteria in sour liquid; while Lactobacillus and Lactococcus species accounted for only 7.94 and $0.39 \%$ of bacteria in sour liquid, respectively (Figure 1). We conclude that Acetobacter, Pseudomonas, and Lactobacillus are the dominant bacteria in the sour liquid.

\section{Isolation of Flocculating Strains}

In total, 86 bacteria, 20 yeasts, and 10 molds were isolated from the sour liquid on TJA and Rose-Bengal media; they were inoculated and cultured in the sweet potato juice medium to identify strains with flocculating activity. Eight strains exhibited flocculating activity. These eight isolates were all bacterial strains, with a rod shape and chain-like arrangement of cells, and were identified as Lactobacillus by $16 \mathrm{~S}$ rDNA sequence homology comparisons. The yeasts and molds did not show any starch-flocculating activity, indicating that Lactobacillus was the dominant flocculating microorganism in the sweet potato sour liquid. The most pronounced flocculating activity among the flocculating strains was observed during the fermentation with Lactobacillus strain L1. Strain L1 was subsequently identified as L. paracasei subsp. paracasei based on its colony character, morphological, and physiological characteristics, as well as $16 \mathrm{~S}$ rDNA sequence homology referencing Bergey's Manual of Systematic Bacteriology; accordingly, it was named L. paracasei subsp. paracasei L1. This strain was deposited in the China General Microbiological Culture Collection Center (CGMCC, no. 4163).

\section{Distribution of the Flocculating Activity in Cell Culture}

The distribution of flocculating activity in cell culture, i.e., its association with the cells and extracellular secretions of L. paracasei subsp. paracasei L1, was investigated. It was conclude

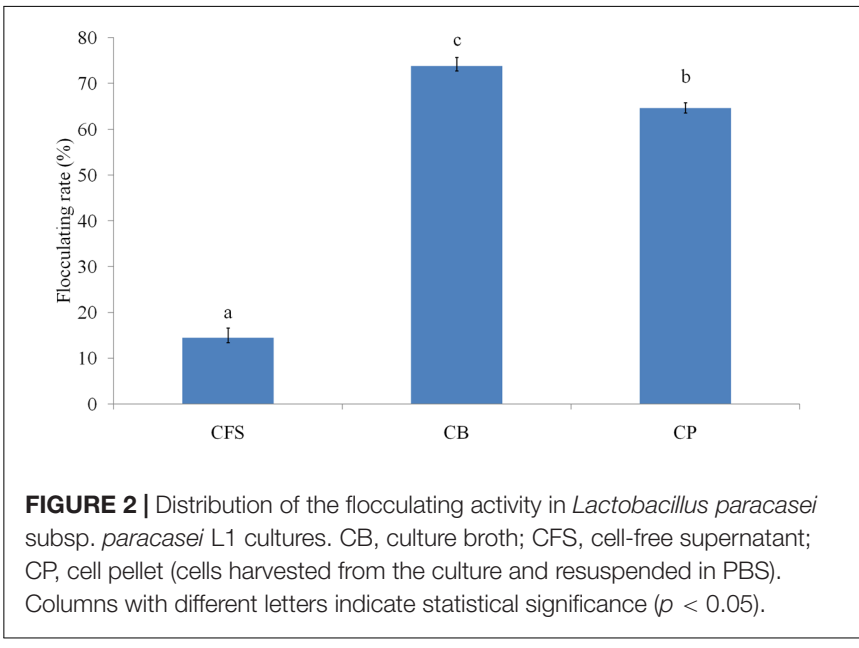

that more than $85 \%$ of the flocculating activity was cellassociated, and less than $15 \%$ of the activity was associated with the extracellular secretions (Figure 2).

\section{Changes of Starch Granule Size in Suspension Associated with a Treatment with $L$. paracasei subsp. paracasei L1 Cultures}

The size of starch granules before and after treatment with L. paracasei subsp. paracasei L1 cultures was evaluated with Microtrac S3500 laser grain size analyzer. The average particle size, $\mathrm{D}_{50}$, also called the median diameter, denotes a cumulative $50 \%$ point of diameter (or $50 \%$ pass particle size). The $\mathrm{D}_{50}$ (the average particle size) of starch granule size increased, from 2.286 to $5.450 \mu \mathrm{m}$, in the presence of $L$. paracasei subsp. paracasei L1 cells, suggesting that the starch granules formed massive floccules (Figure 3). 


\section{Microscopic Observation of Starch Granules Flocculated by L. paracasei subsp. paracasei L1 Cultures}

The size distribution of starch granules before the addition of bacteria was homogeneous and uniform, as observed under an optical microscope at a magnification of $100 \times$ (Figures 4A,B). In the presence of bacteria, the starch granules rapidly aggregated and formed massive floccules. Furthermore, SEM analysis revealed that the L. paracasei subsp. paracase $\mathrm{L} 1$ cells adhered to the surface of starch granules (Figures 5A-D). Multiple bacterial cells adhered to starch granules surface and also to each other, thus forming bridge-like structures linking starch granules and forming the aggregated floc.

\section{$\zeta$ Potential of Solutions during Flocculation}

$\zeta$ Potential of the starch suspension was initially a lot lower than that of $L$. paracasei subsp. paracasei $L 1$ cell suspension in sweet potato juice medium (Table 1). After the addition of cells to the starch suspension $(10 \%, \mathrm{v} / \mathrm{v})$, the potential was closer to zero. According to the DLVO theory, this indicated that the starch granules were in a very unstable state and readily formed a floc precipitation. Both the starch and the cells were negatively charged in water, indicating that the starch-bacterium adhesion was not effected by electrostatic interactions.

\section{The Effect of Physical, Chemical, and Enzymatic Treatments of $L$. paracase $i$ subsp. paracasei L1 Cells on Their Flocculating Ability}

The effect of various treatments on the flocculating ability of L1 cells was investigated to determine the nature of the flocculation factor on the cell surface, and the nature of the interacting force between the cells and starch granules. As shown in Figure 6, the flocculating activity was sensitive to heat treatment, but not to $\alpha$-amylase or lysozyme treatments, indicating that the surface polysaccharide of $L$. paracasei subsp. paracasei L1 did not mediate the flocculation. In contrast, the flocculating activity of cells was affected by UV, ultrasonic treatment, trichloroacetic acid, and lithium chloride, which are all protein denaturants. Furthermore, trypsin treatment significantly reduced the flocculating activity of cells. Collectively, these results indicated that bacterial surface proteins play a role in flocculation.

Flocculation was slightly affected by Tween 80 . This suggested an absence of hydrophobic interactions between L. paracasei subsp. paracasei L1 cells and starch granules; similarly, electrostatic interactions did not occur because both starch granules and cells were negatively charged in water (vide supra). Moreover, these interactions were likely specific because glucose and maltose significantly inhibited the flocculation (Figure 6).
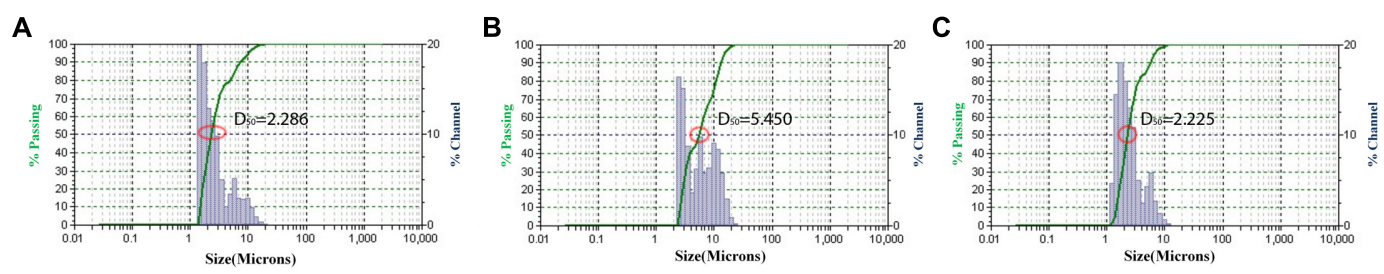

FIGURE 3 | The effect of flocculation on starch granule size. (A) Particle size of starch granules in starch suspension before flocculation. (B) Particle size of starch granules in starch deposition after flocculation. (C) Particle size of starch granules in the supernatant after flocculation.

\section{A}

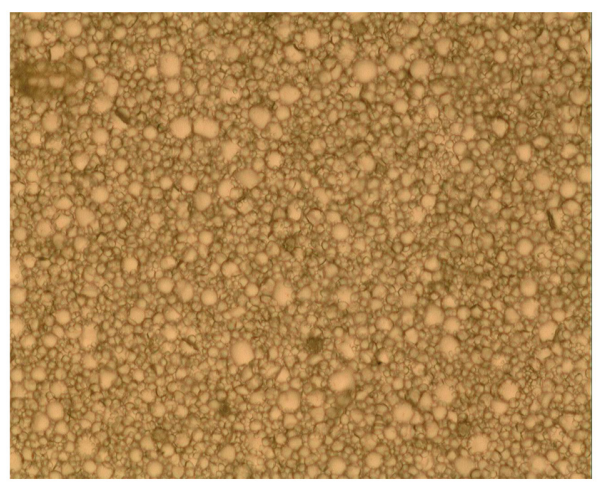

B

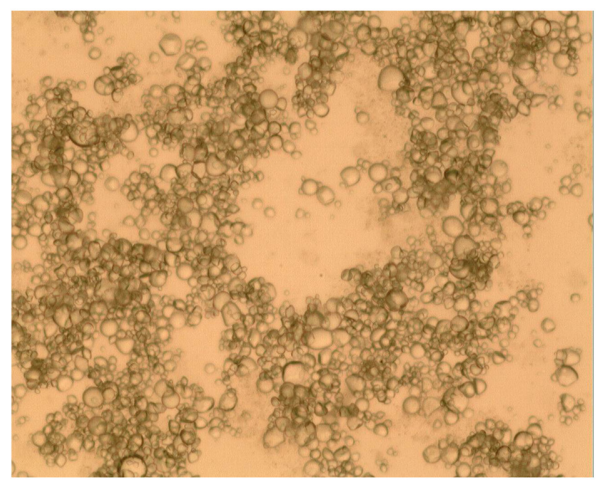

FIGURE 4 | Optical micrograph of starch granule aggregation. Sweet potato starch milk before (A) and after (B) the addition of L. paracasei subsp. paracasei L1 cultures $(100 \times)$. 
A

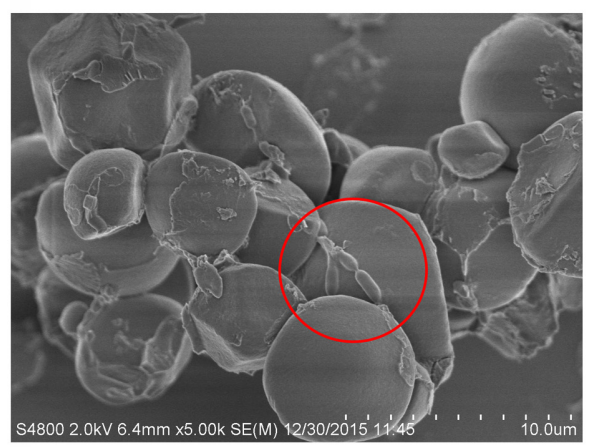

C

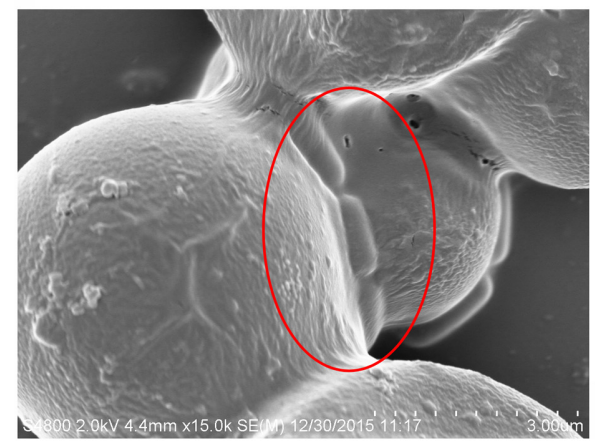

B

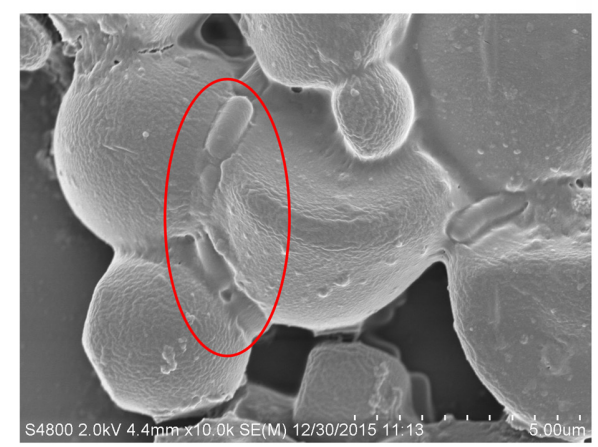

D

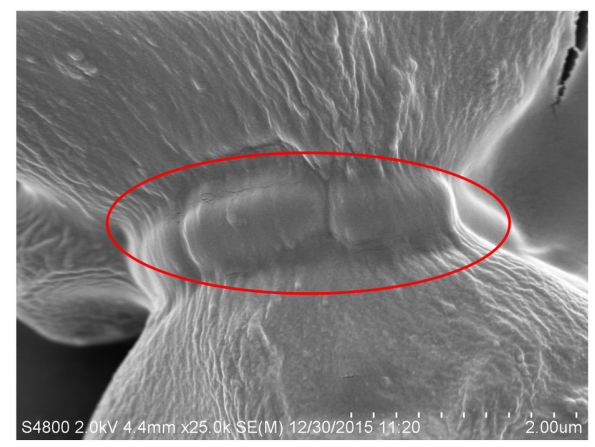

FIGURE 5 | Scanning electron micrograph (SEM) of starch granules with the adhering L. paracasei subsp. paracasei L1 cells. (A) 5,000x; (B) 1,000×; (C) 15,000x; (D) $25,000 \times$.

\section{Identification of Candidate Starch-Binding Proteins}

Surface proteins from L. paracasei subsp. paracasei L1 extracted by the guanidine hydrochloride method were incubated with starch granules. After a series of non-specific washes, proteins adhering to the starch granules were removed by re-suspension in PBS containing $100 \mathrm{mM}$ maltose. Ten candidate starch-binding proteins were then identified by LC-ESI-MS/MS: three of these proteins were glycolytic enzymes; two were identified as the translation elongation factor $\mathrm{Tu}$; one was a cell wall hydrolase; one was a surface antigen; one was lyzozyme M1; one was a glycoside hydrolase; and one was an uncharacterized proteins (Table 2). Mascot score for these hits was $>100$. None of the proteins were detected in the control.

TABLE 1 | Changes in the $\zeta$ potential during flocculation.

\begin{tabular}{|c|c|}
\hline Sample & $\zeta$ Potential (mV) \\
\hline Starch suspension & $-13.97 \pm 0.23^{a}$ \\
\hline Cultures of L1 & $-0.49 \pm 0.02^{\mathrm{c}}$ \\
\hline Starch suspension with adding $10 \%$ cultures of L1 & $-2.29 \pm 0.02^{b}$ \\
\hline
\end{tabular}

Values are presented as means $\pm S D$. Values with different letter designations within the same row are significantly different $(p<0.05)$.

\section{DISCUSSION}

Sour liquid, whether from sweet potato or mung bean, is used as a microbial flocculant and plays a role in promoting the precipitation of starch during preparation for starch (Research Groups of Sour Liquid, 1974; Xu and Liu, 1980). Nevertheless, data on the dominant flocculating microbes are inconsistent. Acetobacter, Lactobacillus, and Pseudomonas are dominant in the sweet potato sour liquid, yet all the strains screened in the current study that exhibited flocculating activity belonged to the Lactobacillus genus. Notably, Lactobacillus sp. were also the first species discovered to flocculate starch (Research Groups of Sour Liquid, 1974; Wei and Qun, 2007). On the other hand, L. lactis is responsible for starch flocculation and no other microorganisms has the ability to flocculate starch in mung bean sour liquid (Research Groups of Sour Liquid, 1974; Xu and Liu, 1980; Wei and Qun, 2007). Lactococcus is also present in the sweet potato sour liquid but was not isolated in the current study, perhaps because of its low numbers. The difference in nutritional components of the sweet potato and mung bean may account for the discrepancy in dominant bacteria responsible for the flocculation. L. paracasei subsp. paracasei L1 and L. lactis have some common features, which may be associated with their flocculating activity. First, both are lactic acid bacteria that can decrease the $\mathrm{pH}$ of the sour liquid. The acidic environment 


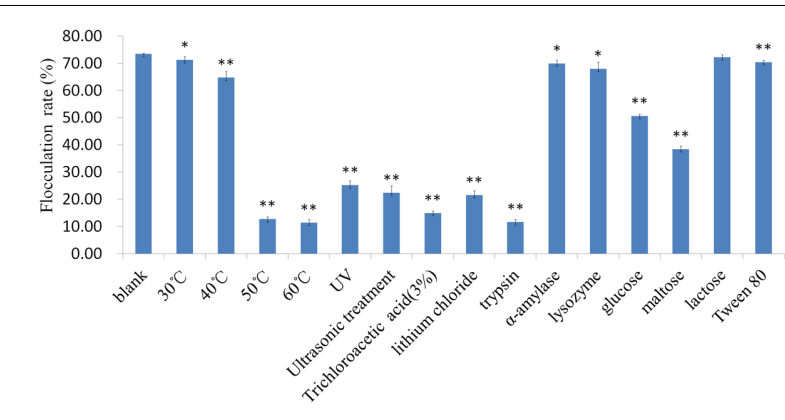

FIGURE 6 | Effects of various treatments of $L 1$ cells on their flocculation. Differences between FR with cells after various treatments and control group were analyzed statistically using $t$-test. ${ }^{*} p<0.05,{ }^{*} p<0.01$.

is considered indispensable for facilitation of the flocculation of starch in sour liquid. Normally, the sour liquid flocculating activity peaks at $\mathrm{pH} 4.5$ (Research Groups of Sour Liquid, 1974). Second, the cells of both species were arranged in a chain after cell division. The flocculating activity is high when the microbial flocculant forms linear higher-order structures. In contrast, the flocculating activity is low when the microbial flocculant has a branching structure (Biggs et al., 2000; Brostow et al., 2007; Hjorth and Jørgensen, 2012). In the current study, the chain-like arrangement of bacterial cells facilitated starch flocculation.

According to the distribution of flocculating activity, the microbial flocculant may be generally classified into two groups: one located on the microbial cell surface, and one in the culture solution (Brostow et al., 2007; Bhattacharya et al., 2017; Liu et al., 2017). In the current study, more than $85 \%$ of the flocculating activity was associated with the L1 cells, while less than 15\% of the activity was associated with the culture liquid. The L1 cells and starch granules interacted via specific, rather than electrostatic or hydrophobic, interactions because both the cells and granules are negatively charged in water. Furthermore, the flocculating activity of L1 cells was visibly inhibited by glucose or maltose, but was not precise by Tween 80 . As such, the $\zeta$ potential and repulsion decreased from $-13.97 \pm 0.23^{\mathrm{a}} \mathrm{mv}$ to $-2.29 \pm 0.02^{\mathrm{b}} \mathrm{mv}$. Multiple L1 cells adhere to a single starch granule. Subsequently, many starch granules were connected by L1 cells that served as bridging agents coagulating the starch granules, thereby increasing the starch granule size, and resulting in the formation of massive flocs and easy deposition. During flocculation, the chain-like arrangement contributed to starch precipitation. Therefore, the flocculation of starch by these cells was consistent with the bridging mechanism that is essential for microbial flocculants shown in other studies (Aljuboori et al., 2016; Raj et al., 2016; Du et al., 2017).

It is prerequisite for the flocculation that $L$. paracasei subsp. paracasei L1 adhere to starch. Other bacteria, such as Bifidobacterium species, $V$. cholerae, B. thetaiotaomicron, and L. amylovorus, also adhere to starch granules; the mechanisms of their adhesion all appear to involve cell surface proteins (Reeves et al., 1996; Crittenden et al., 2001; Ryan et al., 2006; Niderman-Meyer et al., 2010). In the current study, based on SEM observations, the adhesion factors were located on L1 cell surface. The chemical component of the flocculating factors was then evaluated by physical, chemical, and enzymatic treatments of cells, to verify whether cell surface proteins rather than whole cell peptidoglycan or other polysaccharides of $L$. paracasei subsp. paracasei $\mathrm{L} 1$ were involved in the adhesion.

We identified 10 candidate proteins that were involved in the L1 cell-starch interaction; most of them were known to function as adhesins on the cell surface of intestinal bacteria. The identified cell wall hydrolase had the highest Mascot score (455), which indicated that this protein was highly likely to be as identified. Cell wall hydrolases catalyze the cleavage of peptidoglycan sugar or peptide chains (Claes, 2012). Similarly, lysozyme M1 (1,4- $\beta-N$ acetylmuramidase) was detected on the L1 cell surface (Mascot score of 183). These hydrolases play important roles in the regulation of cell wall growth, turnover, and maintenance, and in the separation of daughter cells. Hydrolase is also found on the cell wall of Lactobacillus rhamnosus GG (LGG), often near the mature septa of exponential cells, exhibiting D-glutamylL-lysyl endopeptidase activity in zymogram assays (Nadkarni et al., 2014). Mutation of the cell wall hydrolase in LGG impedes normal separation of daughter cells and the cells are arranged in rather long and overly extended chains (Claes, 2012; Smokvina et al., 2013; Nadkarni et al., 2014). In this bacterium, the hydrolysis of muropeptides in the cell wall also likely affects daughter cell separation and regulates the length of the cell chain structure. The unusual chain structure might reflect the increase in steric hindrance that effectively blocks the interaction between

TABLE 2 | Candidate starch-binding proteins.

\begin{tabular}{|c|c|c|c|c|}
\hline Protein & Accession number & MM/pl & Seq cov/pep match & Mascot score \\
\hline Cell wall hydrolase & $\operatorname{tr} \mid \mathrm{S} 2 \mathrm{~N} 653$ & $41513 / 8.93$ & $25 / 11$ & 455 \\
\hline Surface antigen & $\operatorname{tr|}$ A0A0C9P9Z1 & $42463 / 6.97$ & $9 / 6$ & 199 \\
\hline Phosphoglycerate kinase & $\operatorname{tr} \mid \mathrm{K} 6 \mathrm{QCV} 8$ & $39603 / 5.51$ & $16 / 11$ & 311 \\
\hline Enolase & $\operatorname{tr} \mid \mathrm{AOA0C9Q4L1}$ & $47058 / 4.73$ & $9 / 8$ & 234 \\
\hline Elongation factor Tu & $\operatorname{tr} \mid$ AOAOC9PFS8 & $43546 / 4.87$ & $12 / 11$ & 232 \\
\hline Elongation factor Tu & sp| Q88VE0 & $43350 / 4.95$ & $7 / 7$ & 131 \\
\hline Lyzozyme M1 (1,4-beta-N-acetylmuramidase) & $\operatorname{tr} \mid$ S2NSV8 & $100512 / 6.74$ & $9 / 7$ & 183 \\
\hline Glyceraldehyde-3-phosphate dehydrogenase & $\operatorname{tr} \mid$ AOAOC9PWLO & $36912 / 5.68$ & $3 / 3$ & 139 \\
\hline Uncharacterized protein & $\operatorname{tr} \mid \mathrm{AOAOF} 4 \mathrm{KSCO}$ & $41048 / 8.59$ & $11 / 10$ & 130 \\
\hline Glycoside hydrolase & $\operatorname{tr|}$ AOAOB8U0A4 & $49407 / 4.93$ & $7 / 4$ & 105 \\
\hline
\end{tabular}


the bacterial surface and starch granules. Hence, appropriate chain length regulated by cell wall hydrolase might aid the flocculation of starch by the bridging mechanism. In the current study, we show for the first time the involvement of this protein in the adhesion of L. paracasei subsp. paracasei to starch granules.

Four identified starch-binding proteins were associated with glucose metabolism. Three of them were glycolytic enzymes, namely, phosphoglycerate kinase (PGK, Mascot score 311), enolase (ENO, 234), and glyceraldehyde-3-phosphate dehydrogenase (GAPDH, 139); the fourth one was identified as a glycoside hydrolase (score 139). These sugar-metabolizing enzymes are found in most bacterial cells and play a role in sugar catabolism or degradation of such complex carbohydrates as lactose or starch (Ramiah et al., 2008; Glenting et al., 2013). We asked how these glycolytic enzymes and glycoside hydrolase promote the adhesion of L1 cells to starch granules. On the one hand, the starch granules act as stable surfaces in starch milk, and might facilitate the adhesion of L1 cells because bacteria prefer to grow on solid surfaces rather than in the surrounding aqueous phase (Zobell, 1943; Bäckhed et al., 2005; Boone and Tyrrell, 2012). On the other hand, these proteins, as sugarmetabolizing enzymes, might be available to degrade starch or the products of its decomposition if they are also involved in cellular adhesion, providing energy and sustaining bacterial survival. Corn starch that is flocculated by the sour liquid has low amylase content and small-volume average granule size, high swelling capacity, and high solubility, which suggests that starch is metabolized by bacteria in the sour liquid (Chang et al., 2006; Li et al., 2008). Consequently, the presence of glycolytic enzymes and glycoside hydrolase on L1 cell surface could play a role in acquiring and metabolizing starch. SEM analyses of the intestines of mice maintained on a standard high-polysaccharide chow diet revealed that the bacterial communities assemble on small undigested or partially digested food particles (Bäuerl et al., 2010). Glycolytic enzymes and glycoside hydrolase are produced by $B$. thetaiotaomicron, a prominent mutualist in the distal intestine of adult human (Lebeer, 2010). Whole-genome transcriptional profiling of $B$. thetaiotaomicron revealed that a high-polysaccharide chow diet is associated with a selective upregulation of a subset of SusC and SusD paralogs that bind to and import starch, a subset of glycoside hydrolases, and genes encoding enzymes involved in the delivery of mannose, galactose, and xylose to the pentose phosphate pathway (Liu and Shen, 2007a,b; Deng et al., 2013; Li et al., 2015). Similarly, adhesion to starch might facilitate the hydrolysis of starch and its products, including glucose, by glycolytic enzymes and glycoside hydrolase located either on the cell surface or inside L1 cells. Hence, the bacterium may efficiently use starch and colonize it, surviving under these conditions.

\section{REFERENCES}

Aljuboori, A. H. R., Uemura, Y., and Thanh, N. T. (2016). Flocculation and mechanism of self-flocculating lipid producer microalga Scenedesmus quadricauda, for biomass harvesting. Biomass Bioenergy 93, 38-42. doi: 10.1016/j.biombioe.2016.06.013

\section{CONCLUSION}

As determined by $16 \mathrm{~S}$ rDNA sequencing and traditional microbiology techniques, Lactobacillus was the dominant flocculating bacterial genus in the sweet potato sour liquid. L. paracasei subsp. paracasei L1 strain with a high flocculating activity was isolated, and the flocculation mechanism of its adhesion to starch was investigated. Our results showed that the L. paracasei subsp. paracasei L1 cells specifically bound starch granules and linked these starch granules to form large flocs by bridging. This accelerated starch deposition. The starch-binding proteins on the surface of $L$. paracasei subsp. paracasei L1 cells were extracted using guanidine hydrochloride, and 10 proteins with Mascot scores $\geq 100$ were identified by mass spectrometry. These proteins are also present, as adhesion molecules, on the cell surface of other probiotic bacteria. Their role in bacterial starch metabolism, functional properties, and potential applications in adhesion to starch or other materials should be further investigated.

\section{AVAILABILITY OF DATA AND MATERIAL}

Eight strains exhibited flocculating activity. These eight isolates were all bacterial strains, and were identified as Lactobacillus by $16 \mathrm{~S}$ rDNA sequence homology comparisons. Sequences of this project have been deposited in the NCBI sequence read archive (https://www.ncbi.nlm.nih.gov/genbank/) under GenBank accession numbers: KY952217 (L1); KY952218 (LL1); KY978461 (L28); KY978462 (L36); KY978463 (L53); KY978464 (S07); KY978465 (S10); KY978466 (S32).

\section{AUTHOR CONTRIBUTIONS}

LZ, YX, and XhL performed all experiments and wrote the paper. YY, XoL, HZ, and ZZ conducted the experiments and data analysis. All authors read and approved the manuscript.

\section{ACKNOWLEDGMENTS}

The authors gratefully acknowledge financial support from the National Natural Science Foundation of China (Grant No. 31301499), Natural Science Foundation of Liaoning (File No. 2014022052), Natural Science Foundation of Liaoning (File No. 2014022046).

Anastasi, A., Varese, G. C., and Marchisio, V. F. (2005). Isolation and identification of fungal communities in compost and vermicompost. Mycologia 97, 33-44. doi: 10.1080/15572536.2006.11832836

Bäckhed, F., Ley, R. E., Sonnenburg, J. L., Peterson, D. A., and Gordon, J. I. (2005). Host-bacterial mutualism in the human intestine. Science 307, 1915-1920. doi: $10.1126 /$ science. 1104816 
Bäuerl, C., Pérezmartínez, G., Yan, F., Polk, D. B., and Monedero, V. (2010). Functional analysis of the p40 and p75 proteins from Lactobacillus casei bl23. J. Mol. Microbiol. Biotechnol. 19, 231-241. doi: 10.1159/00032 2233

Beck, H. C., Madsen, S. M., Glenting, J., Petersen, J., Israelsen, H., Nørrelykke, M. R., et al. (2009). Proteomic analysis of cell surface-associated proteins from probiotic Lactobacillus plantarum. FEMS Microbiol. Lett. 297, 61-66. doi: 10.1111/j.1574-6968.2009.01662.x

Bhattacharya, A., Mathur, M., Kumar, P., Prajapati, S. K., and Malik, A. (2017). A rapid method for fungal assisted algal flocculation: critical parameters \& mechanism insights. Algal Res. 21, 42-51. doi: 10.1016/j.algal.2016.10.022

Biggs, S., Habgood, M., Jameson, G. J., and Yan, Y. D. (2000). Aggregate structures formed via a bridging flocculation mechanism. Chem. Eng. J. 80, 13-22. doi: 10.1016/S1383-5866(00)00072-1

Blanton, L. V., Charbonneau, M. R., Salih, T., Barratt, M. J., Venkatesh, S., Ilkaveya, O., et al. (2016). Gut bacteria that prevent growth impairments transmitted by microbiota from malnourished children. Science 351:aad3311. doi: $10.1126 /$ science.aad 3311

Boone, T. J., and Tyrrell, G. J. (2012). Identification of the actin and plasminogen binding regions of group b streptococcal phosphoglycerate kinase. J. Biol. Chem. 287, 29035-29044. doi: 10.1074/jbc.M112.361261

Brostow, W., Pal, S., and Singh, R. P. (2007). A model of flocculation. Mater. Lett. 61, 4381-4384. doi: 10.1016/S1383-5866(00)00072-1

Chang, Y. H., Lin, C. L., and Chen, J. C. (2006). Characteristics of mung bean starch isolated by using lactic acid fermentation solution as the steeping liquor. Food Chem. 99, 794-802. doi: 10.1016/j.foodchem.2005.07.060

Claes, I. J. (2012). Genetic and biochemical characterization of the cell wall hydrolase activity of the major secreted protein of Lactobacillus rhamnosus GG. PLoS ONE 7:e31588. doi: 10.1371/journal.pone.0031588

Coombs, J. T., and Franco, C. M. M. (2003). Isolation and identification of actinobacteria from surface-sterilized wheat roots. Appl. Environ. Microbiol. 69, 5603-5608. doi: 10.1128/AEM.69.9.5603-5608.2003

Crittenden, R., Laitila, A., Forssell, P., Mättö, J., Saarela, M., Mattila-Sandholm, T., et al. (2001). Adhesion of bifidobacteria to granular starch and, its implications in probiotic technologies. Appl. Environ. Microbiol. 67, 3469-3475. doi: 10.1128/AEM.67.8.3469-3475.2001

Deng, F. M., Mu, T. H., Zhang, M., and Abegunde, O. K. (2013). Composition, structure, and physicochemical properties of sweet potato starches isolated by sour liquid processing and centrifugation. Starch 65, 162-171. doi: 10.1002/star. 201200106

Donaldson, G. P., Lee, S. M., and Mazmanian, S. K. (2016). Gut biogeography of the bacterial microbiota. Nat. Rev. Microbiol. 14, 20-32. doi: 10.1038/nrmicro 3552

Dong, H. C., An, S. M., Chun, S., Yang, E. C., Selph, K. E., Lee, C. M., et al. (2015). Dynamic changes in the composition of photosynthetic picoeukaryotes in the northwestern Pacific Ocean revealed by high-throughput tag-sequencing of plastid 16s rRNA genes. FEMS Microbiol. Ecol. 17:fiv170. doi: 10.1093/femsec/ fiv170

Du, Q., Wei, H., Li, A., and Yang, H. (2017). Evaluation of the starch-based flocculants on flocculation of hairwork wastewater. Sci. Total Environ. 60, 1628-1637. doi: 10.1016/j.scitotenv.2017.06.029

Glenting, J., Beck, H. C., Vrang, A., Riemann, H., Ravn, P., Hansen, A. M., et al. (2013). Anchorless surface associated glycolytic enzymes from Lactobacillus plantarum, 299v bind to epithelial cells and extracellular matrix proteins. Microbiol. Res. 168, 245-253. doi: 10.1016/j.micres.2013. 01.003

Hjorth, M., and Jørgensen, B. U. (2012). Polymer flocculation mechanism in animal slurry established by charge neutralization. Water Res. 46, 1045-1051. doi: 10.1016/j.watres.2011.11.078

Lebeer, S. (2010). Host interactions of probiotic bacterial surface molecules: comparison with commensals and pathogens. Nat. Rev. Microbiol. 8, 171-184. doi: 10.1038/nrmicro2297

Li, X., Wang, C., Lu, F., Zhang, L., and Yang, Q. (2015). Physicochemical properties of corn starch isolated by acid liquid and 1 -cysteine. Food Hydrocoll. 44, 353-359.

Li, Z., Liu, W., Shen, Q., Wei, Z., and Tan, B. (2008). Properties and qualities of vermicelli made from sour liquid processing and centrifugation starch. J. Food Eng. 86, 162-166. doi: 10.1016/j.jfoodeng.2007.09.013
Lian, B., Chen, Y., Zhao, J., Teng, H. H., Zhu, L., and Yuan, S. (2008). Microbial flocculation by bacillus mucilaginosus: applications and mechanisms. Bioresour. Technol. 99, 4825-4831. doi: 10.1016/j.biortech.2007. 09.045

Lin, W. H., Hwang, C. F., Chen, L. W., and Tsen, H. Y. (2006). Viable counts, characteristic evaluation for commercial lactic acid bacteria products. Food Microbiol. 23, 74-81. doi: 10.1016/j.fm.2005.01.013

Liu, W., and Shen, Q. (2007a). Structure analysis of mung bean starch from sour liquid processing and centrifugation. J. Food Eng. 79, 1310-1314. doi: 10.1016/ j.jfoodeng.2006.04.012

Liu, W., and Shen, Q. (2007b). Studies on the physicochemical properties of mung bean starch from sour liquid processing and centrifugation. J. Food Eng. 79, 358-363. doi: 10.1016/j.jfoodeng.2006.01.065

Liu, Z., Wei, H., Li, A., and Yang, H. (2017). Evaluation of structural effects on the flocculation performance of a co-graft starch-based flocculant. Water Res. 118, 160-166. doi: 10.1016/j.watres.2017.04.032

Muyanja, C. M., Narvhus, J. A., Treimo, J., and Langsrud, T. (2003). Isolation, characterisation and identification of lactic acid bacteria from bushera: a Ugandan traditional fermented beverage. Int. J. Food Microbiol. 80, 201-210. doi: 10.1016/S0168-1605(02)00148-4

Nadkarni, M. A., Chen, Z., Wilkins, M. R., and Hunter, N. (2014). Comparative genome analysis of Lactobacillus rhamnosus clinical isolates from initial stages of dental pulp infection: identification of a new exopolysaccharide cluster. PLoS ONE 9:e90643. doi: 10.1371/journal.pone.0090643

Niderman-Meyer, O., Zeidman, T., Shimoni, E., and Kashi, Y. (2010). Mechanisms involved in governing adherence of Vibrio cholerae to granular starch. Appl. Environ. Microbiol. 76, 1034-1043. doi: 10.1128/AEM. 01533-09

O'Riordan, K., Muljadi, N., and Conway, P. (2001). Characterization of factors affecting attachment of bifidobacterium species to amylomaize starch granules. J. Appl. Microbiol. 90, 749-754. doi: 10.1046/j.1365-2672.2001.01304.x

O’Toole, G. A. (2016). Classic spotlight: Bacteroides thetaiotaomicron, starch utilization, and the birth of the microbiome era. J. Bacteriol. 198, 2763. doi: 10.1128/JB.00615-16

Piotrowska, A., Gosiewski, T., Bulanda, M., and Brzychczy-Wloch, M. (2016). Using of the 16S rDNA sequencing for identification of Lactobacillus species. Med. Dosw. Mikrobiol. 2016, 5-11.

Raj, P., Batchelor, W., Blanco, A., de la Fuente, E., Negro, C., and Garnier, G. (2016). Effect of polyelectrolyte morphology and adsorption on the mechanism of nanocellulose flocculation. J. Colloid Interface Sci. 481, 158-167. doi: 10.1016/ j.jcis.2016.07.048

Ramiah, K., van Reenen, C. A., and Dicks, L. M. (2008). Surface-bound proteins of Lactobacillus plantarum 423 that contribute to adhesion of caco- 2 cells and their role in competitive exclusion and displacement of Clostridium sporogenes and Enterococcus faecalis. Res. Microbiol. 159, 470-475. doi: 10.1016/j.resmic. 2008.06.002

Reeves, A. R., D’Elia, J. N., Frias, J., and Salyers, A. A. (1996). A Bacteroides thetaiotaomicron outer membrane protein that is essential for utilization of maltooligosaccharides and starch. J. Bacteriol. 178, 823-830. doi: 10.1128/jb. 178.3.823-830.1996

Reeves, A. R., Wang, G. R., and Salyers, A. A. (1997). Characterization of four outer membrane proteins that play a role in utilization of starch by Bacteroides thetaiotaomicron. J. Bacteriol. 179, 643-649. doi: 10.1128/jb.179.3.643-649.1997

Research Groups of Sour Liquid (1974). Why can sour liquid precipitate starch? Acta Sci. Nat. Univ. Pekinensis S1, 57-66. doi: 10.13209/j.0479-8023. 1974.040

Rodriguez-Sanoja, R., Oviedo, N., and Sanchez, S. (2005). Microbial starch-binding domain. Curr. Opin. Microbiol. 8, 260-267. doi: 10.1016/j.mib.2005.04.013

Ryan, S. M., Fitzgerald, G. F., and Sinderen, D. V. (2006). Screening for and identification of starch-, amylopectin-, and pullulan-degrading activities in bifidobacterial strains. Appl. Environ. Microbiol. 72, 5289-5296. doi: 10.1128/ AEM.00257-06

Shipman, J. A., Berleman, J. E., and Salyers, A. A. (2000). Characterization of four outer membrane proteins involved in binding starch to the cell surface of Bacteroides thetaiotaomicron. J. Bacteriol. 182, 5365-5372. doi: 10.1128/JB.182. 19.5365-5372.2000

Smokvina, T., Wels, M., Polka, J., Chervaux, C., Brisse, S., Boekhorst, J., et al. (2013). Lactobacillus paracasei comparative genomics: towards species 
pan-genome definition and exploitation of diversity. PLoS ONE 8:e68731. doi: 10.1371/journal.pone.0068731

Wei, Z., and Qun, S. (2007). The effects of chemical pre-treatment of one precipitating bacteria and Lactococcus lactis As1.9 on their starch precipitating ability. Sci. Technol. Food Ind. 28, 123-126.

Xu, H., and Liu, M. L. (1980). A starch-agglutinating factor on the cell wall of Streptococcus lactis strain? Electron microscopic observation. Acta Microbiol. Sin. 20, 276-279. doi: 10.13343/j.cnki.wsxb.1980.03.009

Xu, Y., Yang, H., Zhang, L., Su, Y., Shi, D., Xiao, H., et al. (2016). Highthroughput sequencing technology to reveal the composition and function of cecal microbiota in Dagu chicken. BMC Microbiol. 16:259. doi: 10.1186/s12866016-0877-2

Zobell, C. E. (1943). The effect of solid surfaces upon bacterial activity. J. Bacteriol. $46,39-56$.
Conflict of Interest Statement: The authors declare that the research was conducted in the absence of any commercial or financial relationships that could be construed as a potential conflict of interest.

The reviewer GP and handling Editor declared their shared affiliation, and the handling Editor states that the process nevertheless met the standards of a fair and objective review.

Copyright (C) 2017 Zhang, Yu, Li, Li, Zhang, Zhang and Xu. This is an open-access article distributed under the terms of the Creative Commons Attribution License (CC BY). The use, distribution or reproduction in other forums is permitted, provided the original author(s) or licensor are credited and that the original publication in this journal is cited, in accordance with accepted academic practice. No use, distribution or reproduction is permitted which does not comply with these terms. 